\title{
ISB News November 2009
}

\author{
(C) ISB 2009
}

\section{From the Secretary}

I am pleased to announce that the "Internal Site" (member only pages) within the ISB web site: http://www. biometeorology.org are now completed. The link to these pages is now visible near the bottom of the left column on the main page. Current members of the society will be provided with a username and password that will allow them to login to this portion of our site. These pages will allow on-line access to current and past copies of the Biometeorological Bulletin, as well as all issues of the
International Journal of Biometeorology. They also will allow a simple form of on-line voting for Executive Board candidates in future elections. I hope that you find these new additions useful. As always, please feel free to contact me with any thoughts or suggestions you might have regarding any ISB matters.

\section{Mark D. Schwartz}

ISB Secretary

mds@uwm.edu 